\title{
Un modelo para analizar la representación simbólica del escándalo de corrupción política desde la teoría del framing: aplicación al 'caso Umbra'
}

\section{A model to analyze the symbolic representation of the political corruption scandal from the framing theory: application to the 'Umbra case'}

Dra. Rocío Zamora Universidad Católica San Antonio de Murcia (UCAM) rzamora@pdi.ucam.edu

Ddo. Juan Antonio Marín Albaladejo Universidad Católica San Antonio de Murcia (UCAM)

juan marin82@hotmail.com

Recibido: 13 de junio del 2011 Aceptado: 07 de septiembre 2011

\begin{abstract}
Resumen
Lo que algunos ya llaman una "cultura política del escándalo" (Barkin, 1999; Thompson, 2001; Castells, 2009) ha supuesto el reconocimiento del poder de los medios en la construcción simbólica del escándalo, a partir del énfasis en ciertos marcos interpretativos con los que se narran las conductas que condicionan la percepción pública de los escándalos políticos. Este trabajo se centra en la representación simbólica de los escándalos de corrupción política. El análisis de la cobertura periodística sobre un caso de gran actualidad en Murcia, el 'caso Umbra', demuestra que, además de por el relato políticotécnico, legal y moral, los escándalos de corrupción política pueden ser también enmarcados desde el enfoque reputacional, es decir, a partir de preocupación por el deterioro de la imagen que la proliferación de escándalos de corrupción política ofrece sobre un territorio concreto y sus instituciones.
\end{abstract}

\section{Abstract}

We live in, as some scholars called, a "scandal political culture" (Barkin, 1999; Thompson, 2001; Castells, 2009) that has supposed the recognition of the media power in the symbolic construction of scandals, where the emphasis in certain interpretive frames with which behaviours are narrated determine public perceptions of the political scandals. This article 
focuses on the symbolic representation of political corruption scandals. The analysis of the media coverage on this great current importance case in Murcia, called the 'Umbra' case, demonstrates that, besides the political- technical, legal and moral, the political corruption, scandals can be framed also from the reputation approach, that is to say, from the worried deterioration on the public image that political corruption scandals proliferation supposes on a concrete territory and his institutions.

Palabras clave: Escándalo político, corrupción política, framing, cultura política, poder político.

Keywords: political scandal, political corruption, framing, political culture, political power.

Sumario: 1. Aclaraciones conceptuales sobre el escándalo de corrupción política. 2. La mediación del escándalo político: Los encuadres y la narración. 3. Estudio de un escándalo de corrupción urbanística: El 'caso Umbra'. 3.1. Urbanismo local y corrupción en España. 3.2. Antecedentes. 3.3. El 'caso Umbra' como objeto de estudio. 3.4. Hipótesis y objetivos. 3.5. Diseño metodológico. 3.6. Resultados. 4. Conclusiones. 5. Bibliografía. 6. Notas.

Summary: 1. Conceptual framework on the political corruption scandals. 2. The mediation of the political scandal: frames and narratives. 3. The study of a scandal of urban development corruption: the ' Umbra Case'. 3.1. Local urbanism and corruption in Spain. 3.2. Precedents. 3.3. The ' Umbra case ' as main study object. 3.4. Hypothesis and objetives. 3.5. Methodology. 3.6. Results. 4. Conclusions. 5. References. 6. Notes.

\section{Aclaraciones conceptuales sobre el escándalo de corrupción política}

La corrupción y el escándalo son dos conceptos muy relacionados, pero distintos. De hecho, el término escándalo primero se representa, a menudo, en los medios bajo el manto del segundo, y es utilizado frecuentemente en la cobertura de los casos de corrupción política en los títulos y cintillos de secciones especiales, funcionando como una etiqueta de las historias presentadas (Canel y Sanders, 2005 y 2006).

Un análisis del debate sobre la relación entre cultura política y medios de comunicación (Janowitz y Schulze, 1979; Amadeo, 1999 y 2008; Bennett y Entman, 2001; Thompson, 2001; Sanders, 2009) muestra la importancia de ambos fenómenos en la definición de las concepciones y actitudes comunes de los ciudadanos hacia la política y los personajes de la vida pública, una relevancia que, según las investigaciones precedentes, está motivada por la capacidad que tienen los medios de difundir contenido simbólico y el poder de construcción social de la realidad que reside en sus marcos de interpretación y representación. 
Los factores claves para comprender el vínculo entre la corrupción política y el escándalo político reflejan la validez del axioma anteriormente señalado. En primer lugar, en la época moderna es imprescindible que la corrupción política se haga visible mediáticamente para que dé lugar al escándalo. En segundo lugar, se ha reconocido el poder de los medios en la construcción simbólica del escándalo, a partir del énfasis en ciertos marcos interpretativos con los que se narran las conductas corruptas y que condicionan el desarrollo y la percepción pública de los escándalos políticos (Giglioli, 1996; Arroyo, 1997; Canel y Sanders, 2005 y 2006).

No obstante, es preciso señalar las diferencias entre la corrupción política y el escándalo político. Así, de la literatura (Johnston, 1996; Malem, 1997; Garzón, 1997; Kjellberg, 2000; Villoria, 2006) se desprende que la corrupción política es la transgresión de las leyes, o de los principios éticos en los que se fundamenta el sistema político o un tipo de moralidad cívica, con relación a lo que constituye un abuso de la función pública, con el fin de obtener un beneficio privado directo o indirecto, material o inmaterial, pudiendo afectar de esta forma a lo que se considera socialmente como el interés general o el funcionamiento propio de dicho sistema. Mientras que se podría definir el escándalo político como: "Una reacción de indignación del público contra un agente político al que se adscribe una conducta que es percibida como un abuso de poder o como una deslealtad hacia las reglas que regulan el cargo que ejerce" (Malem, 1997:84) [1].

Por consiguiente, sin un proceso de acciones y reacciones en los medios de comunicación, sobre el comportamiento de las instituciones o actores implicados, no se desarrolla el escándalo (Amadeo, 1999; Canel y Sanders, 2005). Del contacto entre la corrupción y el escándalo político surgirían, por tanto, tres posibilidades (Villoria, 2006: 57): a) situaciones en las que se mezclan el escándalo y la corrupción; b) situaciones en las que hay corrupción, pero que no se llegan a conocer, o porque aunque se conozcan no generan un discurso de crítica socialmente compartido; c) escándalos que se originan sin que haya corrupción política, como suele ocurrir en numerosos escándalos de naturaleza sexual, o cuando se basan en acusaciones falsas.

Para clarificar más en qué caso de los citados anteriormente nos encontramos en una determinada situación, conviene tener en cuenta una tipología del escándalo. En la línea que apunta Thompson (2001: 167 y ss.), se pueden distinguir tres tipos de escándalo político: Los escándalos sexuales que tienen lugar en la esfera política, al originarse por la transgresión de los códigos morales sobre el sexo por parte de los sujetos políticos, o incluso de su entorno; los escándalos político-financieros, que son los que conlleva la mala utilización de los recursos económicos; y los escándalos de poder, que implican determinados abusos en el ejercicio del poder político. Nos vamos a centrar en los escándalos político-financieros y de 
poder, por la relación de ambos tipos de escándalos con formas de corrupción política. Por lo que, en consonancia con la definición que hemos ofrecido de dicho fenómeno social, consideramos que generalmente se pueden denominar también como "escándalos de corrupción política".

Una vez consideradas las diferencias entre la corrupción y el escándalo político, así como también entre los distintos tipos de escándalo, nos vamos a detener en el escándalo de corrupción política y los aspectos relativos a su representación simbólica a través de los medios de comunicación. Pero antes, debemos observar que el desarrollo de los mass media y los cambios en la forma de hacer política en las democracias liberales, transitando hacia una cada vez mayor 'mediatización' de la esfera pública y personalización de la política, han contribuido a situar los escándalos en el centro de la vida pública, de forma que algunos autores hablan de una "cultura" o "política del escándalo" (Barkin, 1998; Thompson, 2001; Castells, 2009).

\section{La mediación del escándalo político: Los encuadres y la narración}

Una vez realizadas las pertinentes aclaraciones conceptuales sobre el escándalo de corrupción política, conviene preguntarse por la importancia que tienen los contextos culturales y temporales en el desarrollo de este fenómeno y su representación mediática. En este sentido, hay que tener presente la consideración de Jiménez (1995:15) sobre el escándalo como un proceso abierto en el que el significado que se conceda a la conducta generadora del escándalo dependerá de la interpretación que otorguen a la acción diversos sectores de las elites -entre los que juegan un gran papel los medios- en un contexto determinado. Por otra parte, si atendemos la cuestión desde las teorías sobre el framing, bajo cuya perspectiva abordamos este análisis, podemos recordar la importancia que conceden a la cuestión cultural Canel y Sanders (2006:59) en la definición que establecen del frame como: "Contenido manifiesto (que incluye elementos simbólicos) que puede evocar contenido ausente y que, haciendo uso de resonancias culturales, ayudan a hacer más comprensible el mundo social, a la vez que implican un juicio sobre el mismo".

Por tanto, el surgimiento y las formas en que se desarrolla un escándalo "vienen moldeadas por el peculiar conjunto de convenciones y expectativas que son propias de la forma cultural en que se desencadena" (Thompson, 2001, 166).

Pero los medios no sólo transmiten los símbolos presentes en la sociedad, sino también los marcos que se derivan del proceso de producción de la información, la propia organización, los valores y actitudes de los periodistas o la cultura periodística respectiva (Shoemaker y 
Reese, 1991; Sádaba, La Porte y Virgili, 2007), por lo que en el resultante proceso de transmisión reticular de significados, los medios ocupan un papel de "filtro simbólico", adoptando un determinado discurso o enfoque sobre los acontecimientos.

A la hora de identificar los encuadres de la narración sobre un escándalo, no sólo partimos de los diferentes patrones de análisis aplicables a las coberturas de cualquier asunto, sino que también se pueden utilizar las características peculiares del escándalo de corrupción que se derivan de las investigaciones realizadas. Así, en una investigación anterior (Zamora y Marín, 2010) se propuso, tras una revisión bibliográfica y documental, una tipología de los encuadres noticiosos característicos de las informaciones sobre escándalos de corrupción política. Como conclusión, se concretaron seis news frames de los que se puede partir en análisis deductivos sobre esta cuestión: "personificación", "comparación", "corrupción generalizada", "reacción popular", "botín conquistado" y "depuración de responsabilidades".

Para un análisis a partir de los géneros que ofrecen claves de interpretación al lector, como el editorial y los artículos de opinión y análisis, consideramos conveniente tener en cuenta las funciones que destaca Entman (1993: 52) en su definición del encuadre: "promover una definición del problema, una interpretación causal, una evaluación moral y/o la recomendación de solución para el asunto". Este autor explica, en una obra anterior (1991: 11), que el empleo de ciertas imágenes y palabras "tiende a ser coherente con un dominio discursivo establecido, con una serie de ideas asociadas que forman el modo de razonar acerca de un tema". Desde esta perspectiva, propone analizar los enfoques dominantes a partir de la identificación y definición de los personajes, las etiquetaciones o categorizaciones, las generalizaciones y la atribución de responsabilidad determinada por unas causas.

Canel y Sanders (2006) parten de las dimensiones propuestas por Entman, y añaden al analizar la cobertura de escándalos el escrutinio de asociaciones y códigos culturales, así como también del uso de la "noticia icono" para establecer conexiones temáticas. Ésta se da cuando "una historia completa, una narración o un conflicto se asocia y representa por un suceso único que cristaliza en una imagen que domina la narración originaria y modifica el enfoque de otras noticias posteriores" (Bennett y Lawrence, 1995). Este frame se constata con fuerza cuando palabras como "escándalo" o "Watergate" recrean todo un mundo de significados en la memoria colectiva (Canel y Sanders, 2005). Una frase de un personaje, objetos, como los trajes del 'caso Gürtel', o imágenes como, por ejemplo, las que se mostraban en una casa del "cerebro" de la presunta trama revelada en el 'Caso Malaya' (un cuadro de Miró en el cuarto de baño, animales disecados, trofeos de caza...), se convierten, con frecuencia, en el símbolo de un escándalo o de un fenómeno social. 
La importancia de los iconos de la corrupción se revela, también, en la narración de los distintos escándalos, donde es común el empleo de imágenes y términos con fuertes resonancias culturales o que apelan a la experiencia previa de una sociedad. Así, podemos encontrar referencias con gran calado en la cultura popular como, por ejemplo, a personajes de películas sobre la mafia o a escándalos con gran impacto en otra época.

Como subraya Amadeo (1999: 337), además de la "dramatización de los casos", se debe distinguir otro frame, la "tematización" de la corrupción, enmarcándola como un problema global, situada en un contexto y con unas consecuencias. Aquí es importante, por tanto, ver si las interpretaciones se producen en un marco episódico o temático (lyengar, 1991). A la dramatización puede contribuir, según Arroyo (1997:342), la "personificación", ya que "la narración de los hechos se provee de fuerza dramática representando en personajes concretos las posiciones de la controversia... y, por tanto, simplificando".

También se observan pautas recurrentes en la presentación de los personajes, enmarcados como víctimas / villanos (Protess et al., 1991). Como indica Giglioli (1996), la "extremada simplificación ('héroes' contra 'villanos') "respeta fielmente la estructura formal y el contenido temático de la narrativa popular". Así, el escándalo es "resultado de la fabulación, de la asignación a determinados individuos renombrados de los papeles clásicos del drama, de su estigmatización o idealización" (Arroyo, 1997). Igualmente, se pueden medir las relaciones entre los personajes en términos de oposición 'nosotros' (y nuestras buenas acciones) y 'los otros' (y sus malas acciones) (Van Dijk, 1999; Canel y Sanders, 2006: 109). Debido a que la prensa está envuelta en la revelación de los escándalos de corrupción política, esta confrontación puede tomar en la narración, en algunos casos, el cariz de un enfrentamiento entre los políticos implicados y la prensa, que ejercita el papel de perro guardián (Canel y Sanders, 2006).

En la tradición investigadora es común la distinción entre dos tipos de discursos que los medios pueden generar: un discurso técnico y un discurso moral (Entman, 1991; Canel y Sanders, 2006: 132 y ss.; Giglioli, 1996). Cada uno de estos discursos se manifiesta en los términos empleados y en las referencias presentes o latentes agrupándolos en diferentes categorías. De acuerdo con los análisis de Giglioli (1996) sobre el caso Tagentópolis, el discurso técnico puede concebir la corrupción como la consecuencia de causas estructurales, y el discurso moral tiende estar asociado a la "degradación de los culpables y la purificación ritual de la sociedad". Por otro lado, también tenemos que tener presente la clasificación de Amadeo (1999, 274 y ss.), que identifica tres tipos de discursos posibles referidos a los personajes implicados en los casos, articulados también por los términos que se utilizan y que pueden cambiar en las distintas fases del caso: legalista, político y moral. El primero se caracteriza por los términos "referidos al proceso judicial en sí". Los términos 
políticos se refieren "a lo que se plantea en el terreno del poder y en la lucha por la opinión pública". Finalmente, los términos morales "implican directamente una aprobación o sanción ética a los protagonistas".

En líneas generales, se ha sostenido que la prensa local desempeña un papel determinante para la construcción democrática en cuanto a que facilita la participación en la esfera pública de todos los actores sociales, en comparación con lo que supone el nivel nacional. Sin embargo, en estos mismos contextos comunitarios, cabe destacar también una relación tan estrecha entre los periodistas y los políticos locales que pone en tela de juicio hasta qué punto esa misma esfera pública no es más que un espacio de refuerzo e intercambio de intereses mutuos.

Estos condicionamientos del periodismo local, que dificultan la adopción de un papel crítico del poder establecido o de 'perro guardián' (watchdog) de los intereses de la audiencia, se acentúan en los casos en los que la inserción de publicidad institucional se convierte en un soporte de ingresos fundamental para el medio, con lo que la presencia de un escándalo político en la agenda mediática y los marcos de representación utilizados en su narración han llegado en alguna ocasión a diferir entre los medios nacionales y locales en un determinado contexto debido, en parte, a esta circunstancia (Meyer, 2008 y 2009).

Además, junto al carácter hiperlocal o monotemático (Arias, 2009: 126) de muchos cibermedios y el renacimiento en Internet de los confidenciales que distribuyen información y rumores (Parra y Álvarez, 2004: 158; Sánchez, 2008), en gran parte de los medios digitales se da "una especie de extraña mezcla entre información de teletipos y artículos de opinión" que "se refleja en los blogs, en columnas más o menos convencionales y en la presencia ideológica” (López, 2009, citado en González et al. 2009: 53). Estas características del nuevo ciberperiodismo nos conducen a pensar en un nuevo escenario en el que la adopción preferente de modelos profesionales críticos y que pretenden difundir una serie de valores e ideas en el público puede dar lugar a nuevos condicionamientos en la representación de los escándalos de corrupción política en los contextos locales y regionales.

\section{Estudio de un escándalo de corrupción urbanística: El 'caso Umbra'}

\subsection{Urbanismo local y corrupción en España}

El problema de la corrupción política en España ha estado, principalmente, vinculado en los últimos años a la actividad urbanística en el ámbito local. Como muestra de ello, la Fiscalía Anticorrupción mantenía abiertas a finales de 2009 cerca de 730 investigaciones a cargos públicos por este motivo. Además, según el Cuerpo Nacional de Policía, en el periodo 2004- 
2009 se detuvo a un millar de personas en operaciones contra la corrupción en más de un centenar de ayuntamientos, en las cuales se intervinieron bienes valorados en casi tres mil millones de euros. La situación, de la que se han hecho eco diversos medios internacionales, ha llegado a ser denunciada en varios informes del Defensor del Pueblo y considerada como una "forma endémica de corrupción" por el Parlamento Europeo (2009) [2], que amenazó incluso con la retirada a España de los fondos estructurales si no se corregían los abusos urbanísticos. De acuerdo con los datos de la Memoria de la Fiscalía General del Estado del año 2008, los procedimientos judiciales y diligencias previas por casos de corrupción afectan de forma indiscriminada a todos los partidos políticos con representación significativa y en diferentes comunidades autónomas.

En paralelo a este fenómeno, se ha producido un fuerte deterioro de la imagen de la clase política, que, según los últimos barómetros del Centro de Investigaciones Sociológicas (CIS), se afianza como tercer problema para los españoles. Esta tendencia se observa en el conjunto del planeta, donde ha aumentado, con la crisis económica, la percepción de la corrupción, según la organización Transparencia Internacional [3].

La extensión de la corrupción política asociada al urbanismo municipal se ha producido impulsada por la concatenación de varios factores que han sido destacados en varios estudios (Iglesias 2007; Jiménez, 2008; Villoria, 2008; Lapuente, 2009), y que explican el carácter local de la gran mayoría de los escándalos en la última década. En ese sentido, Jiménez (2008) los engloba en tres grandes causas: las peculiaridades del modelo urbanístico español -con un alto impacto de las decisiones administrativas en la multiplicación de las plusvalías de los propietarios del suelo y un gran margen de discrecionalidad de los decisores municipales-, la falta de controles efectivos sobre el funcionamiento de los ayuntamientos y el extraordinario incremento de la construcción de viviendas en España entre los años 1995 y 2006.

Este cóctel 'explosivo' se ha agitado aún más mediante la figura del convenio urbanístico, que permite modificar de forma discrecional los planes generales y recalificar los terrenos en urbanizables mediante acuerdos concretos entre el consistorio y particulares a cambio de compensaciones al municipio, a través de obras de infraestructuras o con pagos en metálico. En la Región de Murcia, se llegaron a rubricar más de 300 convenios que en algunos casos han dado origen a investigaciones judiciales por corrupción. No obstante, a pesar de que la mayor parte de los escándalos políticos de los últimos años ha tenido origen en el ámbito municipal (Jiménez, 2010), la mayoría de los ciudadanos piensa que la corrupción está más presente en la política autonómica o nacional (CIS 2829, enero-marzo de 2010), lo que resulta cuando menos llamativo. 


\subsection{Antecedentes}

En el último lustro, periodo en el que se han reforzado los medios de la Fiscalía para luchar contra la corrupción y se han creado grupos específicos de la Policía y la Guardia Civil contra la delincuencia urbanística, se han multiplicado las detenciones y operaciones policiales por delitos de este tipo en los ayuntamientos españoles, especialmente en las comunidades autónomas que han experimentado un mayor crecimiento del suelo edificado.

En la Región de Murcia, cargos públicos en cerca de la mitad de los 45 ayuntamientos son objeto de investigaciones judiciales en la actualidad, en su mayoría por asuntos urbanísticos. Entre los escándalos con más repercusión se encuentran los de La Zerrichera, Torre Pacheco, Ceutí, San Javier, 'Tótem', 'Ninette', 'Biblioteca' o 'Limusa'. Como resultado, un ex consejero autonómico y ex delegado del Gobierno, cuatro alcaldes y dos ex regidores han sido detenidos, de los cuales tres sufrieron penas de prisión preventiva. En algunos casos, se ha revelado el asentamiento del clientelismo local con la investigación de presuntos intentos de compra de votos a cambio de empleos municipales, o, en otros, la influencia de las estrechas relaciones entre políticos y determinados empresarios a la hora de tomar las decisiones de gobierno. Algunas detenciones han provocado, incluso, la creación de plataformas ciudadanas de apoyo a los implicados, que han sido recibidos como héroes en sus municipios tras salir de prisión, dejando imágenes significativas en la memoria colectiva.

Además, en varias ocasiones los partidos afectados no han depurado responsabilidades, y, como en el caso del PP, a veces se han escudado en denuncias ante la opinión pública de la falta de independencia de la Fiscalía, argumentando el archivo de querellas anteriores.

\subsection{El 'caso Umbra' como objeto de estudio}

En este punto situaremos las claves y el contexto en el que se enmarca el escándalo concreto de nuestra investigación, exponiendo, de forma breve y sintética, los hechos, personajes y circunstancias que lo rodean.

La investigación judicial

El 'caso Umbra' se reveló el 5 de octubre de 2010, cuando la Unidad Central de la Guardia Civil, en medio de un gran despliegue de medios de comunicación, registró la Gerencia de Urbanismo del Ayuntamiento de Murcia, gobernado por el PP. Además, los agentes abrieron varias cajas fuertes en oficinas bancarias y realizaron otros registros en algunas empresas y domicilios de este municipio y de Madrid, entre los que se encontraba el del presidente del 
club Real Murcia, el empresario Jesús Samper. Dentro de de la operación policial fueron detenidos el director de la Gerencia, un abogado y un ingeniero, y, además, entre una veintena larga de imputados, se encontraban el concejal de Urbanismo, Fernando Berberena -por un presunto delito de prevaricación-, y el presidente del equipo de fútbol de la ciudad.

Las investigaciones, bajo secreto de sumario y emprendidas a instancias de una denuncia de la Fiscalía, se centran, según se ha publicado en diferentes medios, en un presunto trato de favor del Ayuntamiento a algunos empresarios promotores en el marco de seis convenios urbanísticos en el norte de la ciudad, firmados entre 2001 y 2006 . Entre las operaciones inmobiliarias bajo sospecha, se halla la que permitió la aprobación del proyecto para construir el estadio Nueva Condomina, junto a un complejo comercial y una zona residencial para 4.000 viviendas en terrenos que anteriormente estaban calificados como no urbanizables. Como consecuencia, el Consistorio habría dejado de percibir cientos de millones de euros como contraprestaciones por esos acuerdos. Así, las actuaciones judiciales se siguen por presuntos delitos de cohecho, malversación de caudales públicos, prevaricación, negociaciones prohibidas a funcionarios, falsedad en documento mercantil y blanqueo de capitales, entre otros.

\section{Contexto}

La situación política de la Región de Murcia se ha caracterizado desde 1995 por la hegemonía del Partido Popular, que tiene mayoría absoluta en la Asamblea Regional y en la mayor parte de las corporaciones municipales. Al mismo tiempo, la Región ha experimentado hasta el estallido de la crisis económica actual un fuerte crecimiento del PIB, impulsado por la mayor actividad de la construcción y el aumento demográfico.

En lo que respecta a la novedad del escándalo, que salió a la luz ocho meses antes de un proceso electoral, con todas las repercusiones que dicho aspecto puede conllevar, cabe señalar que a pesar de las múltiples investigaciones abiertas en los ayuntamientos de la Región, es la primera de ellas en la que se imputa a un edil del equipo de Gobierno del ayuntamiento encabezado por Miguel Ángel Cámara, secretario general del PP en la Región de Murcia, cuyo nombre ha figurado en los análisis periodísticos sobre la sucesión del presidente de la Comunidad, Ramón Luis Valcárcel. En este sentido, se da la circunstancia de que apenas tres semanas después de que estallara el escándalo, se revelaron conversaciones telefónicas intervenidas judicialmente al empresario Enrique Ortiz, principal imputado en el 'caso Brugal', en las que se menciona al alcalde y varios concejales, en relación al proceso de adjudicación de las obras del tranvía del municipio. 


\section{Repercusiones}

El caso despertó desde el principio una amplia cobertura por parte de los medios locales, que tras el interés por los primeros registros y detenciones tuvo su punto álgido en las comparecencias judiciales del dueño del Real Murcia y el concejal Berberena -que salió del juzgado haciendo con una mano la ' $\mathrm{V}$ ' de la victoria-, alcanzando en algunos momentos grandes dosis de espectáculo, que provocaron, incluso, 'comparaciones' con el revuelo mediático causado por los juicios de los acusados en el 'caso Malaya' en Marbella.

Asimismo, el asunto dio lugar a diferentes reacciones políticas, tanto a nivel local como nacional, así como a diversas cuestiones de análisis y debate en los medios de la Región. Líderes del PP nacional y miembros del Gobierno español polemizaron sobre la imparcialidad de las actuaciones policiales y de la Fiscalía, aludiendo los 'populares' a la existencia de un trato de favor distinto en función de los colores políticos o a una supuesta maniobra de distracción para desviar la atención pública de cuestiones que afectaban al Ejecutivo de Zapatero. Por otro lado, en el ámbito regional, el PP presentó el escándalo como ajeno a esta formación política, mientras que la oposición lo achacó al modelo de desarrollo urbanístico regional.

Las implicaciones que podían tener las cuantías de las fianzas y las medidas cautelares impuestas por el juez -que han provocado numerosos interrogantes sobre la trascendencia del caso-, así como las posibles consecuencias negativas del escándalo sobre la imagen de la Región, la reacción del alcalde del municipio y el futuro de un nuevo proyecto económico encargado al empresario Jesús Samper, han sido otros de los principales aspectos del caso que han estado en el candelero. Como consecuencia del 'caso Umbra', la corrupción ha pasado a ser considerada como el tercer problema para los ciudadanos de la Región, según datos del barómetro del Centro de Estudios Murcianos de Opinión Pública (otoño, 2010) [4].

\subsection{Hipótesis y objetivos}

Este estudio se centra en el estudio de los marcos interpretativos con los que los medios en un contexto local abordan, analizan y se posicionan sobre un caso de corrupción política, y, por tanto, definen su papel en el proceso en el que se construye socialmente el escándalo. Para demostrar una serie de consideraciones que señalaremos a continuación, hemos analizado los enfoques de los medios regionales en los editoriales, artículos de opinión y géneros de análisis del 'caso Umbra'. Así, hemos partido de las siguientes hipótesis:

Hipótesis 1: Junto a los clásicos discursos legalista, político y moral, un muevo marco adquiere una presencia fundamental en la representación simbólica y en la interpretación 
que los medios del contexto regional hacen del 'caso Umbra': el discurso reputacional, o lo que es lo mismo, la preocupación asentada por el deterioro de la imagen que la proliferación de escándalos de corrupción política ofrece de la Región de Murcia y de sus instituciones.

Hipótesis 2: Existe una "cultura periodística del escándalo político" que es diferente en función de si se trata de un medio tradicional local o de un cibermedio que por definición sigue un modelo de watchdog o perro guardián. Esta peculiaridad condiciona el tipo de relato predominante.

A partir de estas hipótesis, esta investigación pretende identificar los discursos predominantes y novedosos sobre la corrupción y el escándalo en el contexto local, comparando, el tratamiento de los distintos medios (prensa tradicional y medio digital). Mediante este análisis, se trata además de comprobar si los medios tratan el caso como un asunto específico o como un problema político global.

Finalmente, nos planteamos reflexionar sobre los atributos con los cuales reconocen los medios a los líderes políticos como consecuencia de la gestión de un escándalo, al observar los juicios de las distintas reacciones, las comparaciones entre las diferentes respuestas, así como las recomendaciones que hacen los medios en este sentido.

\subsection{Diseño metodológico}

Con el fin de comprobar estas hipótesis utilizamos un diseño metodológico basado en el análisis de contenido de todos los editoriales y artículos de opinión y análisis publicados en relación con el caso 'Umbra' por los dos principales diarios regionales, La Verdad y La Opinión, así como por la edición regional de La Razón, y por el cibermedio Vega Media Press.

El periodo de análisis estudiado comprende desde el 5 de octubre de 2010, fecha en la que se revela públicamente este caso, hasta el 6 de noviembre del mismo año, lo que supone algo más de un mes de análisis periodístico. Los criterios para codificar las unidades de análisis comprendían varios bloques (identificación general de documento, aspectos formales de la unidad de análisis, aspectos específicos del contenido gráfico y aspectos específicos del contenido textual) que incluían diferentes categorías vinculadas a las hipótesis de nuestro estudio, cuya información, una vez depurada, fue explotada con el programa estadístico SPSS.15, con el fin de obtener una valoración descriptiva de los resultados mediante el análisis de las frecuencias simples y las oportunas tablas de contingencia.

Para comprobar la relevancia de ciertas palabras más mencionadas en el relato periodístico del caso en cuestión, se utilizó la creación de un cuadro de etiquetado (tag cloud) a partir de 
una relación de las palabras asociadas a los juicios de valor y categorizaciones presentes en el relato. Asimismo, a través de una respuesta abierta, se recogieron las principales metáforas asociadas a los diferentes discursos.

\subsection{Resultados}

Abordaremos la presentación de los resultados empezando por la descripción de los aspectos más formales utilizados en la narración periodística del escándalo, siguiendo por el análisis requerido para comprobar las dos hipótesis de este trabajo. Para ello, nos fijaremos, en primer lugar, en la visibilidad e imagen de los sujetos asociados al caso 'Umbra', así como en la existencia de oposiciones binarias entre los personajes de las que se desprenden atribuciones de responsabilidad. Posteriormente, nos centraremos en el predominio de un relato específico (frame) que haya conformado la opinión periodística sobre este caso, a partir de la relevancia de ciertas palabras vinculadas a los juicios evaluativos y metáforas utilizadas en los textos.

\section{Aspectos formales de la narración sobre el escándalo del caso 'Umbra'}

El seguimiento de las piezas de opinión y análisis publicadas en los medios analizados demuestra, en primer lugar, que el caso 'Umbra' ha sido un asunto de gran interés periodístico, a tenor de las 58 unidades de análisis registradas durante el mes que duró el estudio. Entre todos los medios, hay dos cabeceras que mostraron una mayor preocupación por este asunto: el diario regional La Opinión (con un 39,7\% del total de las unidades) y el cibermedio Vega Media Press (31\%). Por su parte, los diarios La Verdad (17,2\%) y La Razón (12,1\%), presentaron un menor número de piezas.

Tal y como se indica en la Tabla 1, existió una tendencia decreciente en cuanto al número de artículos publicados en los diferentes medios en relación al caso. En general, todos los medios dieron más importancia a lo acontecido durante la primera semana, coincidiendo con las detenciones y la comparecencia judicial de algunos imputados, y posteriormente se redujo la atención mediática durante las semanas posteriores. Existió un ligero repunte durante la cuarta semana, coincidiendo con la revelación de escuchas del caso 'Brugal', en las que el alcalde era directamente aludido y los medios establecieron comparaciones y relaciones entre ambos casos. 


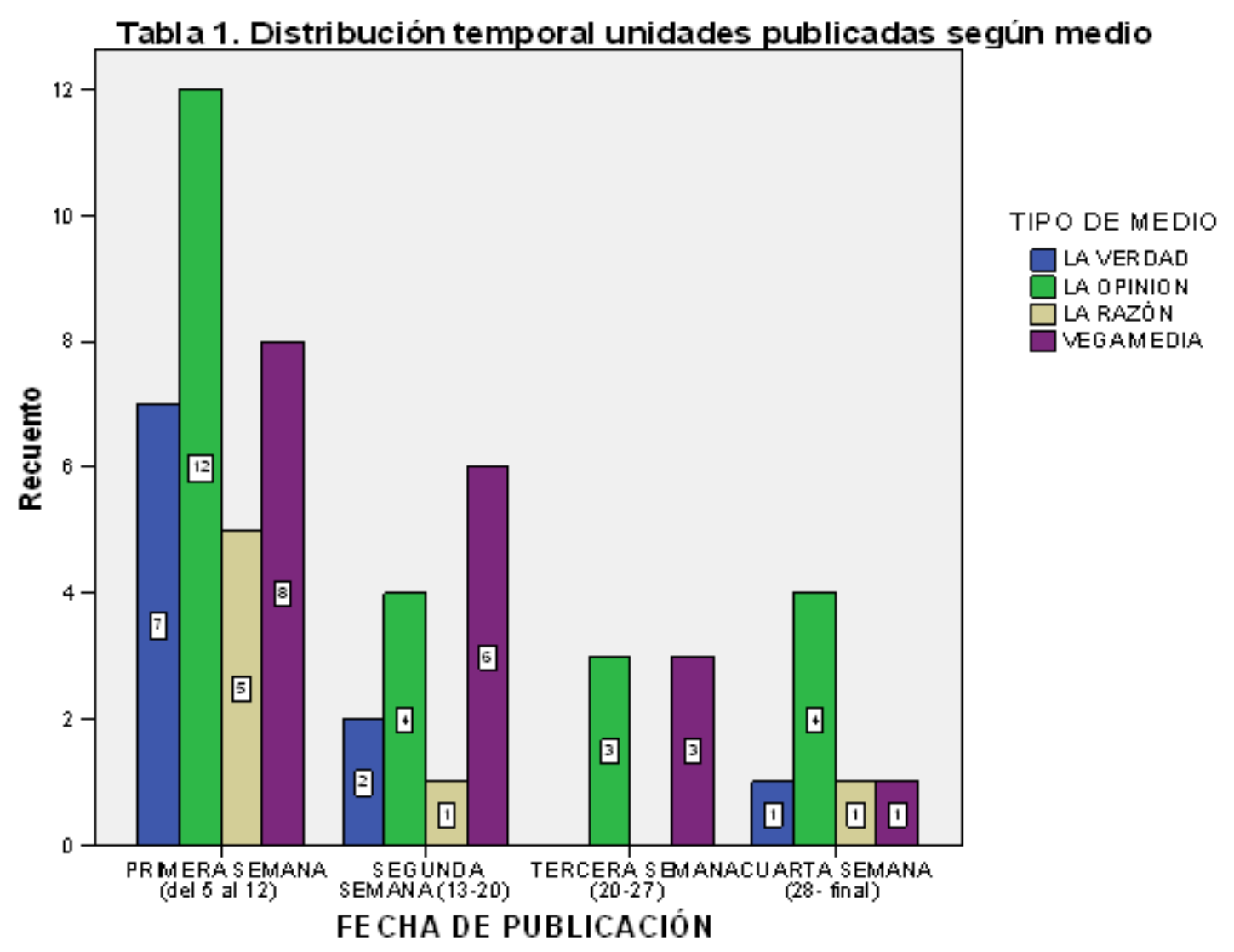

Para hablar del escándalo, la prensa tradicional utilizó mayoritariamente el formato de artículo de opinión (80\%), y en considerable menor medida otros como los análisis 0 informes $(12,5 \%)$ o los editoriales $(5 \%)$. Por su parte, en el cibermedio, la presencia de editoriales como formato para interpretar el escándalo político tiene algo más de presencia $(16,7 \%)$, aunque sigue siendo el artículo y la columna de opinión el formato más representativo $(77,8 \%)$.

\section{Visibilidad de los personajes (personalización del escándalo y atributos)}

El examen tanto del contenido gráfico como del texto revela que los detenidos no son los personajes a los que más atención se presta, sino a los fiscales y Fuerzas de Seguridad del Estado, al alcalde Cámara y prácticamente sólo a los dos imputados (de los más de una 
veintena) con mayor relevancia mediática, el concejal de Urbanismo, Fernando Berberena, y el presidente del Real Murcia, Jesús Samper.

Con respecto al contenido gráfico, el escándalo político, cuando es objeto de opinión y análisis periodístico, no suele incluir ningún elemento gráfico, tal y como ocurrió en nuestro caso de estudio (47,8\% no aparece). En ciertos casos $(32,6 \%)$ se incluyó además una fotografía, en la que, de manera más destacada aparecía el edil de Urbanismo, Fernando Berberena, que se convierte sin duda en la relevancia icónica de este relato. Tanto por su alusión indirecta en los textos, principalmente, como por la aparición también en fotografía, su imagen saliendo de los juzgados haciendo el signo de la victoria se convierte en la imagen icono del 'caso Umbra'.

El alcalde Cámara le sigue en visibilidad, sobre todo en el diario La Verdad, especialmente en la última semana coincidiendo también con la publicación de escuchas del caso 'Brugal'. El diario La Razón, por su parte, concede el protagonismo al fiscal jefe del TSJ, Manuel López Bernal, en un contexto claro, tal como veremos, de fuerte crítica negativa y atribución de responsabilidad en lo sucedido. En el caso de Vega Media el protagonismo de Berberena es muy escaso, y en su lugar aparecen Samper y Cámara juntos, así como los fiscales/jueces.

Si atendemos a los textos, los actores principales son los miembros del poder judicial, a los que se destaca en la mitad de los casos, seguidos por Cámara (34,8\%), Berberena $(32,8 \%)$ y Samper (32,8\%). Las diferencias entre los medios respecto a la relevancia que tienen los personajes en relación a los acontecimientos también se reflejan en los actores destacados en el contenido textual. Así, Vega Media Press concede mayor importancia al presidente (14,5\%), después de los fiscales/jueces (18\%), mientras que el diario La Razón da el protagonismo a la oposición (20'8\%) después de los miembros del estamento judicial (25\%).

Examinando la evolución de la visibilidad de los personajes, los datos demuestran que la representación mediática del caso empezó siendo más técnica pero terminó centrándose en los líderes políticos. Así, en la primera semana en la que se inicia el escándalo, los fiscales/jueces (63,2\% de las unidades publicadas durante ese periodo) y las Fuerzas de Seguridad (40.6\%) son los más citados. En la segunda semana, coincidiendo con su declaración en los juzgados, el dueño del Real Murcia fue un actor relevante $(53,8 \%)$, así como los miembros del poder judicial $(38,5 \%)$ y el presidente Valcárcel $(38,5 \%)$, que empieza a tomar cartas en el asunto incluso antes que el propio alcalde de Murcia. Sin embargo, es Cámara el que toma el protagonismo en las dos últimas semanas analizadas, cuando se filtran escuchas del caso 'Brugal' y algunos medios hacen relaciones con el caso que estudiamos. 
Paralelamente, el análisis del caso 'Umbra' muestra cómo la reacción ante el escándalo de corrupción puede servir como eje a los medios para proyectar una serie de atributos configuradores de la imagen del líder. Así, es recurrente una contraposición entre la imagen de Cámara y la de Valcárcel. El alcalde aparece generalmente como un político honesto ("es verdad que es un hombre que lo tiras al agua y sale seco", La Opinión, 28 de octubre), pero "poco expresivo" (La Opinión, 24 de octubre), que "acostumbra a sacar un comunicado cuando ya se ha conocido el alcance de la onda expansiva" (La Verdad, 10 de octubre), falto de liderazgo en las ocasiones clave ("Como cuando el yacimiento de San Esteban. Nuca está cuando debiera", La Opinión, 6 de octubre) y carente de "iniciativa política" (La Opinión, 24 de octubre). Por el contrario, se describe la "rápida reacción" de Valcárcel, al que se representa como un 'bombero' que sale a la palestra antes "cuando se trata de apagar algún fuego" (La Verdad, 10 de octubre) y que "tiene que salir al quite en los asuntos municipales que no le corresponden" (La Opinión, 24 de octubre), mostrándolo como un comunicador activo y un líder con iniciativa ("ha terciado desde Bruselas dejando otra vez fuera de juego a Cámara", La Verdad, 10 de octubre de 2010; "basta con encenderle un misto para que salte", La Opinión, 24 de octubre). La comparación entre ambos se deja constar además en los dos principales medios regionales con similitudes en la gestión de crisis anteriores ("la rápida reacción del presidente contrasta con la 'invisibilidad del alcalde (otra vez)", La Verdad, 10 de octubre). Asimismo, al alcalde se le pide la depuración de responsabilidades políticas ("tiene la pelota en su tejado. Es necesaria una 'Operación Don Limpio'” La Opinión, 11 de octubre; "debe dimitir", Vega Media Press, 7 de octubre).

Sin embargo, esta tendencia cambia en el cibermedio, con la personalización del escándalo principalmente en la figura del presidente autonómico, cuya reacción se vincula con el "déficit de valores éticos" en un líder que "carece de virtud cívica" (18 de octubre). Por otro lado, el secretario general de los socialistas murcianos es presentado en el medio digital como un político generalmente débil en la crítica de la gestión del partido rival ("autoproclamado 'nuevo azote del PP'... En fin, ipara temblar!", 5 de octubre). En el caso del diario La Razón, este enfoque de los atributos también es diferente, ya que, además de no tratarse la reacción de los líderes del PP, la personalización política del escándalo recae en Saura, tanto en el texto como en el contenido gráfico (acompañado del titular "Aullidos", 12 de octubre), presentándolo de forma muy negativa, como un político irresponsable que hace "daño de manera gratuita" a Murcia, al que "sólo interesa el PP, la imagen" (12 de octubre), y que utiliza, con poco éxito y sin ética, la estrategia política subterránea y los escándalos de corrupción para dañar la reputación del rival ("el trabajo sucio se le reserva a Saura", 6 de octubre). 


\section{El escándalo: los sufridos ciudadanos honrados frente a los corruptos}

Las atribuciones de responsabilidad de los distintos tipos de personajes implicados en este caso de estudio se pueden desprender del análisis de las diferentes oposiciones binarias que se detectan (Protess et al., 1991; Van Dijk, 1999; Canel y Sanders, 2006). En este caso, se ha considerado el esquema narrativo 'héroes' (o 'víctimas') frente a los 'villanos', que encarnan la culpabilidad en los hechos (Protess et al., 1991; Giglioli, 1996).

Como consecuencia, observamos que el principal enfoque utilizado para la narración de este escándalo político concreto ha sido el que se define este caso como un problema de "ciudadanos honrados" que padecen a una clase formada por políticos y otros ciudadanos corruptos $(23,1 \%)$. El otro enfoque predominante es el de fiscales y jueces como 'héroes' que luchan contra los políticos corruptos (19,8\%): "Una problemática política que sitúa a los jueces en difíciles posiciones, pero que se irán resolviendo con cautela y gran profesionalidad" (Vega Media Press, 27 de octubre de 2010). A veces los 'héroes' se presentan también como víctimas de las acciones de partidos con afectados por escándalos de corrupción, que llevan a cabo una "feroz campaña para desprestigiar a los jueces" (Vega Media Press, 10 de octubre de 2010), considerándose que "un ataque a una de estas instituciones es un ataque al Estado" (La Opinión, 9 de octubre, 2010).

En este punto se ha observado, incluso, una lucha de los periodistas (considerados como 'héroes') contra los corruptos, un hecho que se ha podido detectar exclusivamente en el cibermedio ("Estamos hartos de tanta impunidad... nosotros proponemos el mayor respeto por la Justicia y sus profesionales", Vega Media Press, 10 de octubre de 2010). En este contexto, se manifiesta una auto-reivindicación de este medio digital frente a los principales medios tradicionales de la Región, a los que dirige una parte considerable de sus críticas.

Por su parte, el enfoque fiscales/jueces (considerados como 'villanos') contra la clase política corrupta adquiere el carácter contrario en La Razón, donde algunos políticos son víctimas de una Fiscalía politizada 'villana' (40\%) que hace "chapuzas partidarias" (16 de octubre), y en el que el fiscal jefe es un "poli malo" (6 de octubre) o "un perro peligroso" (16 de octubre) cuyo "dueño" son los socialistas y el Gobierno central.

Asimismo, 'los políticos honrados' pueden aparecer como 'víctimas' de otros políticos o ciudadanos corruptos, pagando los platos rotos por estos 'villanos' ("hablan de los 'políticos', así en general... Y es injusto", La Opinión, 7 de octubre), o enfatizándose su combate frente a los envites de los personajes corruptos ("El portero del ladrillo", La Verdad, 17 de octubre; "o se tienen unos principios inamovibles, o al final cae hasta el gato", La Opinión, 7 de octubre). Este encuadre tiene una representación más significativa en La Verdad (donde supone el mismo porcentaje que el esquema de fiscales/jueces versus corruptos (27,3\%). 


\section{Errores técnicos, responsabilidades políticas y repercusiones electorales}

Antes de analizar los tipos de discurso presentes en el relato de los medios regionales sobre el 'caso Umbra', es conveniente señalar el predominio de un enfoque episódico (60,3\%) por encima del temático $(37,9 \%)$. Este dato refleja una tendencia creciente en la narración periodística sobre la corrupción política por centrar la atención en lo anecdótico de cada caso, olvidando el tratamiento de todos los casos en su conjunto como problema público que merece una respuesta política. En el conjunto de los textos examinados, La Verdad (50\%) y Vega Media Press $(44,4 \%)$ son los únicos medios que establecen relaciones con otros casos de presunta corrupción y dedican un mayor tratamiento del escándalo en un contexto global y de problemas estructurales. Por otro lado, la dramatización en la narración del caso adquiere mayor relevancia en los textos de la Razón (85,7\%) y La Opinión (65,2\%).

En cuanto a las categorizaciones y juicios de valor en torno a los implicados, esta investigación demuestra que buena parte de los hechos $(32,8 \%)$ son considerados en un contexto de responsabilidades políticas, en el que los escándalos políticos son atribuidos a errores técnicos o de incompetencia ("tendrá que responder por su falta de diligencia y por no estar atento", La Opinión, 11 de Octubre; "la imputación de Berberena ya constituye algo más que un símbolo, pero todavía es posible considerarla por el hecho de que el concejal es un firmón", La Opinión, 7 de octubre). En muchas ocasiones, dentro de este tipo de discurso político-técnico que es prioritario, se utilizan repercusiones electorales del escándalo de corrupción. Sirvan de ejemplo las nubes de etiquetas (tags cloud) que figuran en la ilustración 1 y que muestran los términos asociados a las evaluaciones vinculadas al relato de este escándalo y en las que vemos palabras del tipo "electoral", "voto", "responsabilidad", "política", "descontrol" "resultados", "público", "respuesta" o "técnicos", como más sobresalientes de un discurso mediático situado en un plano eminentemente político/técnico, en el que las implicaciones políticas del caso son una referencia principal a la hora de abordar el asunto. Este enfoque es especialmente significativo en el diario La Opinión $(43,5 \%)$. 
llustración 1. Nubes de etiquetas con los términos asociados al discurso

\section{La Opinión}

acusaciones

chirrian

caso chiringuito

corrupcion corruptelas

delitos denuncia electoral escandalos etica grave instituciones politica practicas

\section{La Verdad}

acusaciones CaSO chiringuito chirrian colaterales corrupcion corruptelas delitos denuncia electoral escandalos etica grave instituciones practicas responsabilidad sospechatrama voto 


\section{La Razón}

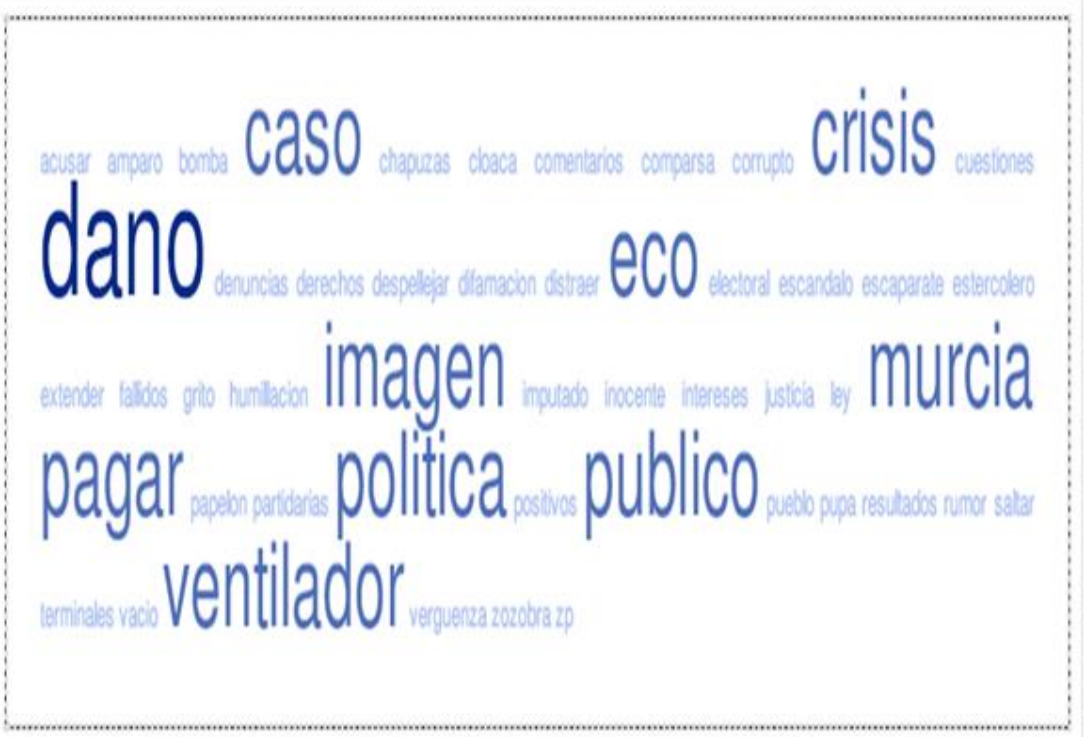

\section{Vega Media Press}

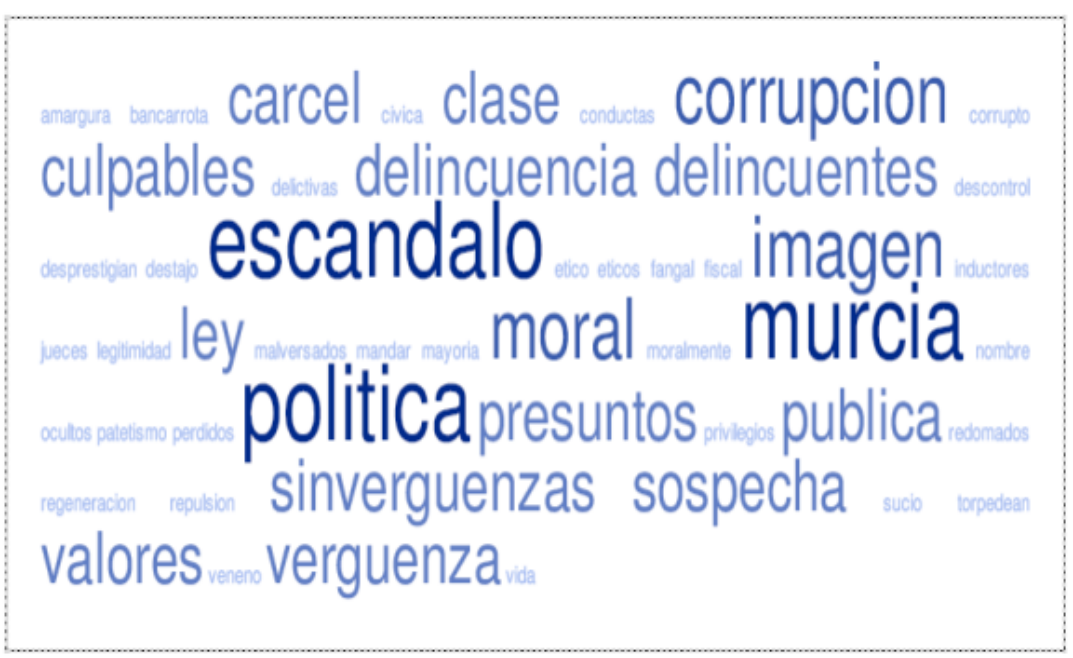

El discurso legal ocupa la segunda posición en la narración de este caso $(27,6 \%)$, lo que supone que prioriza el carácter delictivo del escándalo político o bien mediante referencias directas al proceso legal con términos como "delincuentes", "sospecha", "culpables", "cárcel", "denuncia", "ley", "corrupción", "presuntos" o "delitos", que son más sobresalientes en el 
relato de Vega Media Press, donde llega a alcanzar la mitad exacta de los textos que aparecen.

En tercer lugar, y en la línea de lo que se apuntaba en la primera hipótesis de nuestro trabajo, junto a los discursos antes mencionados, un muevo marco adquiere una presencia fundamental en la representación simbólica y en la interpretación que los medios del contexto regional hacen del 'caso Umbra': el discurso reputacional, o lo que es lo mismo, la preocupación asentada por el deterioro de la imagen que la proliferación de escándalos de corrupción política ofrece de la Región de Murcia y de sus instituciones. En este sentido, hasta un $20,7 \%$ de las piezas publicadas al respecto de este caso sostienen un relato centrado en la preocupación por los efectos de este escándalo sobre la imagen local de Murcia. Este encuadre está presente en todos los medios y es mayoritario en La Razón (42,9\%) y La Verdad (40\%), con abundancia de términos como "daño", "imagen", "ruido", "eco", "ventilador", "alarma", "disparadero", "deteriora", "Murcia" o "Región", asociados a las categorizaciones expresadas en los textos.

En concreto, en cuanto a la responsabilidad del poner "la imagen de la Región a los pies de los caballos" (La Verdad, 16 de octubre), ésta no es sólo atribuida, por parte de la prensa tradicional, a los presuntos corruptos, sino también a los Cuerpos de Seguridad, jueces y fiscales, a los que se pide que tengan en cuenta la repercusión mediática a la hora de efectuar sus acciones ("puso a la Región en el disparadero nacional de una forma excesiva y gratuita"; "se podían haber ahorrado las detenciones", La Verdad, 16 de octubre). En el caso concreto de La Razón, este discurso gira en torno a la crítica al "daño a la imagen de Murcia que costará reparar" (12 de octubre) por una "campaña" orquestada, según el medio, por el PSOE y la Fiscalía, que utilizan el "ventilador sobre el estiércol" (29 de octubre) "con amplio eco mediático" (6 de octubre). Para Vega Media Press, "son los corruptos los culpables de esa amarga erosión" y se presenta, en este contexto, como defensor de la sociedad frente a "los que desprestigian el buen nombre de Murcia con sus fechorías" (13 de octubre), y aboga por la alianza entre jueces/fiscales ("los buenos", 5 de octubre).

El discurso moral, centrado en la preocupación ética por las consecuencias que este tipo de conductas tiene para la sociedad y para el sistema democrático, también adquiere cierto protagonismo (19\%) a través del empleo de términos como "sinvergüenzas", "escándalo", "regeneración", "moral", "ético", "valores", "repulsión", o "sucio", para realizar juicios evaluativos y censurar comportamientos en la escena pública. Este relato está más presente en el medio digital (27,8\%) ("Entre la repulsión, la vergüenza y el patetismo", 5 de octubre), así como en el diario La Opinión (21,7\%) quien se atreve a describir la naturaleza de los corruptos ("pijerío de baja estofa", 12 de octubre; "golfos apandadores", 13 de octubre). 
Si atendemos a la evolución de estos diferentes discursos a lo largo del tiempo incluido en nuestro análisis observamos cómo el discurso legal predomina en la primera semana, periodo en el que se producen las detenciones y registros, dejando paso al relato reputacional, que llega a ser el más característico de la segunda semana de nuestro análisis, y el relato político-técnico, que repunta durante la última semana.

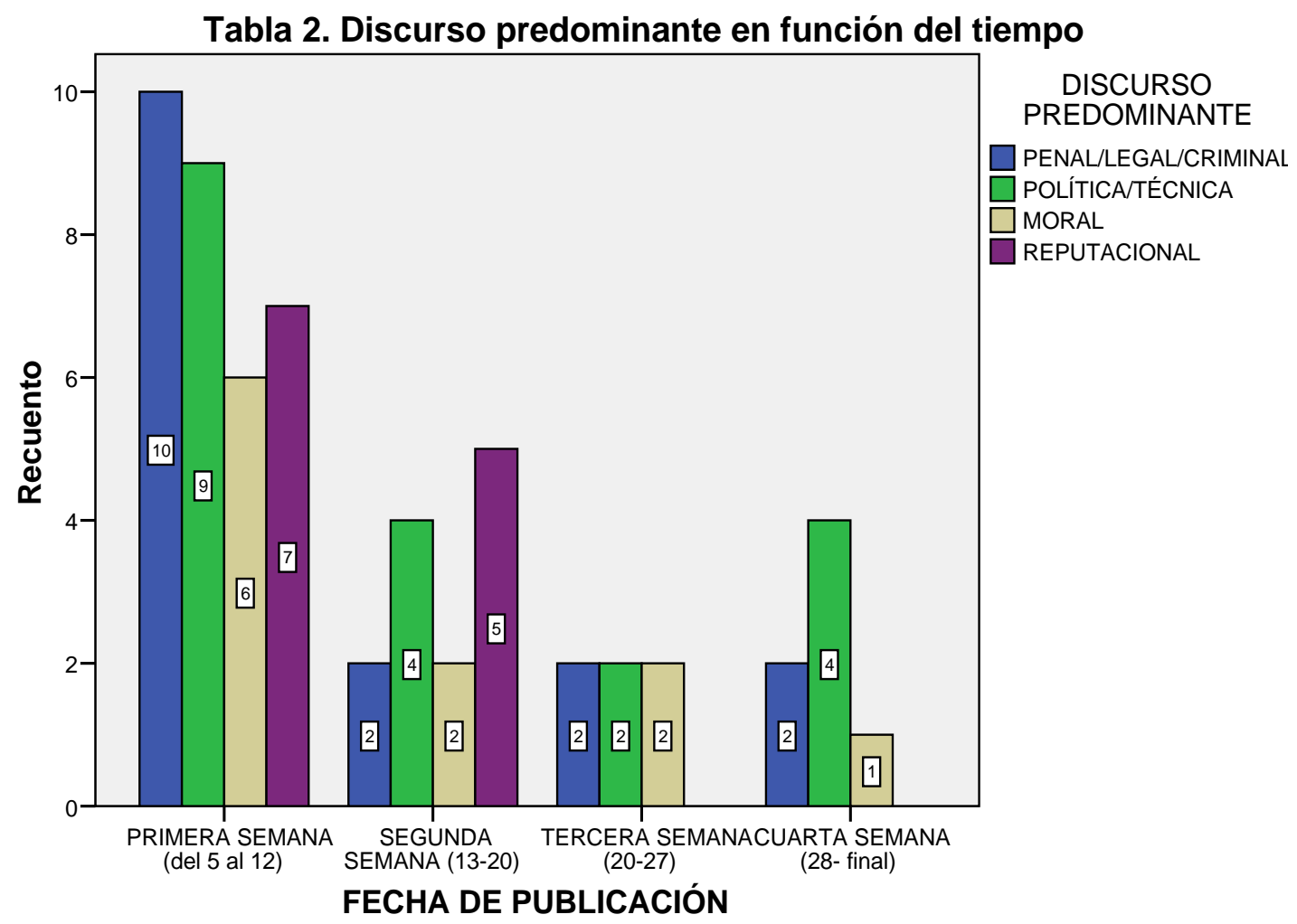

\section{De la Mafia a la fábula moral, pasando por el cáncer, el ruido y las nueces}

Las metáforas en la narración del 'caso Umbra' crean redes de significados que se articulan en torno a los cuatro discursos señalados anteriormente -legal/criminal, político-técnico, moral y reputacional- generando, de esta forma, distintas estructuras de razonamiento o marcos metafóricos sobre los aspectos del escándalo. En este contexto, son recurrentes, entre otras, las referencias cinematográficas, históricas, comparativas, literarias, a la cultura de masas o a imágenes presentes en la memoria colectiva de la sociedad. 
Así, cuando en el discurso se atribuyen responsabilidades legales o criminales, es común encontrar alusiones a la mafia y a películas o series televisivas sobre este fenómeno: "La Murcia Nostra" (acompañado de una imagen de la cinta El Padrino); "convenios muy parecidos a los de don Corleone en Palermo" (Vega Media Press, 5 de noviembre); "Mundo Soprano" (La Opinión, 6 de octubre); "mafia de cuello blanco, los peces más gordos, los más peligrosos de los capos" (Vega Media Press, 13 de octubre). Las comparación con otros casos famosos también es frecuente en este enfoque: "lo de Marbella es 'pecata minuta' comparado con lo de Murcia" (Vega Media Press, 5 de octubre). Otra metáfora destacada es la de la persecución de la corrupción identificada como una 'cacería' ("Se abre la veda", La Razón, 6 de octubre; "estaremos atentos a la caza", Vega Media Press, 13 de octubre) o una 'partida de cartas' (“¿Guarda el fiscal un as en la manga?”, La Verdad, 10 de octubre).

Pero es en los planos político-técnico, donde se sitúa la mayor diversidad de metáforas utilizadas en la narración, abundando en la comparación entre la reacciones de los personajes ("Valcárcel-Cámara, la misma letra y distinta música", La Verdad, 10 de octubre) o identificando la necesidad de depurar responsabilidades con "una limpieza general" (La Opinión, 10 de octubre). Las metáforas son también utilizadas como eje por La Razón para presentar el caso como un "escándalo organizado" (16 de octubre) por la Fiscalía y la oposición: "EI PSRM y el brazo tonto de la ley" (9 de octubre); "sometido al imperio de la guerra política" (29 de octubre); "Fiscalía comparsa" (7 de octubre); "el dueño y responsable del perro peligroso lo llevaba sin bozal y sin atar" (16 de octubre). Por otro lado, Vega Media Press describe la Región recurrentemente como "un enorme cortijo" de Valcárcel (5 de octubre).

El discurso moral está presente en la estigmatización de la clase corrupta, con categorizaciones como "tipos de alta cuna y baja estofa" (La Opinión, 12 de octubre), "manzanas podridas" ( La Verdad, 10 de octubre), o "políticos con estómagos en los que cabe un buque también" (Vega Media Press, 10 de octubre). Igualmente, la dialéctica víctimas/villanos se manifiesta, en el diario La Razón, a través del drama moral ("eso es como la Fábula del Escorpión y la Rana", 9 de octubre).

La preocupación por el deterioro de la imagen del contexto local y sus instituciones se convierte también en una fuente considerable de metáforas en la narración de los medios regionales, especialmente en el diario La Verdad: "Murcia. Levantada en peso" (6 de octubre); "mucho ruido y tres nueces" (16 de octubre).

El término "sombra" (umbra en latín), aludiendo al nombre del caso, también es utilizada en infinidad de ocasiones en los distintos medios para denotar contextos diferentes ("trabajó en la sombra", Vega Media Press, 8 de octubre; "la sombra es el escándalo organizado", La 
Razón, 16 de octubre; "Se ha contagiado de la 'umbra' de esta operación, cuya sombra se ha proyectado en la Junta de Gobierno", La Opinión, 25 de octubre; "todos estamos a oscuras", La Verdad, 7 de octubre).

Por otro lado, cuando la narración de los medios adopta un enfoque temático, se suele representar la corrupción como una enfermedad o una patología social: "ese cáncer que corroe las entrañas de nuestra democracia" (Vega Media Press, 7 de octubre).

\section{Conclusiones}

El estudio realizado sobre la narración periodística de un escándalo de corrupción política, como es el 'caso Umbra', nos permite concluir que, en este caso particular, existió la necesidad de dejar constancia de la posición editorial de los diferentes medios regionales sobre lo que había acontecido, a tenor de la proliferación de editoriales y artículos de opinión y análisis publicados durante el primer mes, desde que se destapó el caso. Este posicionamiento se articuló, generalmente, en torno a los tipos de discurso predominante que caracterizaron el encuadre de cada uno de los medios, y que se definen a partir de las categorizaciones o juicios de valor asociados a una serie de metáforas y palabras clave. Así, los medios regionales abordaron el caso principalmente desde una óptica político-técnica, que se centró en las responsabilidades políticas que se desprenden de los hechos presentados, en los errores técnicos o de competencia profesional de los actores a los que se da visibilidad, así como en las implicaciones que tiene el escándalo en la batalla electoral y por la imagen pública.

No obstante, en este contexto, emerge un marco "reputacional" o de profunda preocupación por el daño que producen los escándalos de corrupción política en la imagen local y de las instituciones murcianas, de forma que este marco condicionó las interpretaciones transmitidas por los medios sobre el caso, manifestándose, además, a partir de dicho enfoque el posicionamiento distinto de cada medio. En este sentido, la atribución de responsabilidad en el deterioro de la imagen de Murcia fue una constante en, prácticamente, todos los medios analizados.

De forma particular, se observaron diferencias en la actitud adoptada por el único cibermedio analizado frente al comportamiento de la prensa tradicional, en el sentido de que el primero utilizó a veces un enfoque metacomunicativo, centrado en el escrutinio o la crítica al tratamiento informativo y editorial otorgado por los medios tradicionales a este escándalo de corrupción, así como en la reivindicación de su condición de espacio de información alternativo mucho más crítico frente al poder, independiente de intereses empresariales o de 
grupos de presión. Precisamente por esta condición, en el cibermedio examinado (Vega Media Press), a diferencia de los otros medios, fue más significativo el discurso legal o criminal y, sobre todo, moral, llegando a realizar un 'juicio público' y de degradación de los presuntos corruptos. Este enfoque diferente adopta en la red una "cultura periodística del escándalo político", en la que son continuas las denuncias sobre la corrupción y tienen una presencia considerable las críticas y las referencias a la cobertura de los medios tradicionales locales a los cuales contrapone su modelo periodístico.

Del análisis también se desprende que el foco de los medios puede correlacionarse con el grado de culpa o de responsabilidad en la solución que los medios atribuyen a los personajes públicos, en la línea de lo que señala lyengar en su teoría del priming (1991). Así, entre las imágenes dominantes de la narración sobresale, tanto por su inclusión en fotografía como por las veces que es aludida en el texto, la del concejal de Urbanismo haciendo el signo de la victoria al salir de los juzgados donde acaba de declarar, convirtiéndose en un símbolo o "noticia icono" de este caso (Bennett y Lawrence, 1995; Canel y Sanders, 2005).

La personalización del escándalo también se refleja en la visibilidad de los líderes políticos donde la reacción ante el escándalo se convierte en un termómetro que mide los atributos que configuran la imagen que da el medio de cada uno de ellos.

\section{Bibliografía}

Amadeo, B. (1999): El proceso de transmisión de significados. La aplicación de la teoría del framing a la cobertura de la corrupción política en Argentina (1991-1996). Tesis inédita, Universidad de Navarra.

---- (2008): Valores democráticos y medios de comunicación masiva. Comunicación efectuada en la Academia Nacional de Ciencias de Buenos Aires, sesión privada extraordinaria.

Arias, F. (2009): "Periodismo local en la red. El caso de Elche digital", en González I., González J.L. \& Carvajal, M. (eds). Reinventar los medios locales. Murcia: Diego Marín.

Arroyo, L. (1997): "Fábulas y fabuladores. El escándalo político como fenómeno de los medios de comunicación", en Laporta, F. y Álvarez, S. (Eds.), La corrupción política (pp. 335-359). Madrid: Alianza Editorial.

Barkin, J. M. (1999): "How Mass Media Simulate Political Transparency". Cultural Values, 3 (4), 393-413.

Bennet, W. L. \& Lawrence, R.G. (1995): "News icons and the Mainstreaming of Social Change". Journal of Communications, 45 (3), 20-39. 
y Entman, R. (2001): “An Introduction”. En Mediated Politics. Communication in the Future of Democracy. New York: Cambridge U. Press.

Canel, M. J. \& Sanders K. (2005): "El poder de los medios en los escándalos políticos: la fuerza simbólica de la noticia icono". Anàlisi, 32, 163-178.

---- (2006): Morality Tales: political scandals and journalism in Britain and Spain in the 1990s. Creskill, New Jersey: Hampton Press INC.

Castells, M. (2009): Comunicación y poder. Madrid: Alianza Editorial.

Dijk, T. A. van (1999): Ideología: un enfoque multidisciplinario. Barcelona: Gedisa

Entman, R. (1991): "Framing US Coverage of International News: Contrasts in Narratives of the KAL and Iran Incidents". Journal of Communication, 41 (4), 6-27.

---- (1993): “Framing: Toward Clarification of a Fractured Paradigm". Journal of Communication, 43 (4), 51-58.

Garzón V. E. (1997): “Acerca del concepto de corrupción”, en Laporta, F. y Álvarez. S. (eds.). op.cit. (pp.39-68).

Giglioli, P. P. (1996): “La corrupción política y los medios de comunicación”. El caso de Tangentópolis. Revista Internacional de Ciencias Sociales, 149.

González I., González J.L. \& Carvajal, M. (eds.). (2009): Reinventar los medios locales. Murcia: Diego Marín.

Iglesias, F. (2007): Urbanismo y democracia. Alternativas para evitar la corrupción. Madrid: F. Alternativas.

lyengar, S. (1991): Is Anyone Responsible? (How TV frames political issues). Chicago: University of Chicago.

Janowitz, M. y Schulze, R. (1979): "Tendencias de la investigación en el sector de las comunicaciones de masas", en Sociología de la comunicación de masas, Miquel de Moragas (ed.), Barcelona: Gustavo Gili.

Jiménez, F. (1995): Detrás del escándalo político. Opinión pública, dinero y poder en la España del siglo XX. Barcelona, España: Tusquets.

---- (2008): "Boom urbanístico y corrupción política en España”. En Pérez Díaz, V. (coord.), Mediterráneo Económico num. 14: Modernidad, crisis y globalización. Problemas de política y cultura. Almería: F. Cajamar.

---- (2010): “Paradojas de la corrupción municipal”. Más poder local. Magazine, 2, 6-7.

Johnston, M. (1996): "La búsqueda de definiciones: la vitalidad de la política y el problema de la corrupción”. Revista Internacional de Ciencias Sociales, 149.

Kjellberg, F. (2000): Corruption as an Analytical Problem: Some Notes on Research in Public Corruption. Presentado en el International Political Science Association XVIII World 
Congress. Quebec, 1-5 agosto. Citado en Villoria, M. (2006): La corrupción política. Madrid: Síntesis.

Lapuente, V. (2009): "Problemas institucionales y corrupción”, en Estefanía, J. (ed.). Informe sobre la democracia en España. Madrid: Fundación Alternativas.

Malem, J.F. (1997): "El fenómeno de la corrupción”, en Laporta, F. y Álvarez, S. (Eds.). op.cit. (pp. 71-90).

Meyer, J. A. (2008): Comunicación política y comportamiento electoral: Agendas públicas y razones de voto en las elecciones municipales de Puebla, en Asociación Mexicana de Investigadores de la Comunicación. Memorias del XX Congreso Nacional. Monterrey, México.

(2009): "Establecimiento de agendas en medios de comunicación: Repercusiones del escándalo mediático Marín-Nacif-Cacho", en Revista Latina de Comunicación Social, 64, 1528. Universidad de La Laguna (Tenerife), recuperado el 17 de octubre de 2010, de http://www.revistalatinacs.org/09/art/02_800_05_Puebla/Jose_Antonio_Meyer_Rodriguez.ht ml DOI: 10.4185/RLCS-64-2009-801-15-28.

Parra, D. \& Álvarez, J. (2004): Ciberperiodismo. Madrid: Síntesis.

Protess, D. L. et al. (1991): The journalism of outrage. Investigative reporting and agenda building in America. New York: Guilford Press.

Sádaba, T., La Porte, M.T., Rodríguez Virgili, J. (2007): La teoría del framing en la investigación en comunicación política. Comunicación presentada en el II Congreso de Comunicación Política, Universidad Complutense, 8 y 9 de marzo.

Sánchez, M. (2008): "Cibermedios de acceso abierto con información confidencial en España como nueva modalidad de confidencialismo online". ZER, 24 (13), 157-181.

Sanders, K. (2009): Comunicating politics in theTwenty-first century. Hampshire (UK): Palgrave Macmillan.

Shoemaker, P. J. \& Reese, S. (1991): Mediating the message. Theories of Influences on Mass Media Content. New York: Longman.

Thompson, J.B. (2001): El escándalo político. Poder y visibilidad en la era de los medios de comunicación. Barcelona: Paidós.

Villoria, M. (2006): La corrupción política. Madrid: Síntesis.

---- (2008): Informe Global 2008 sobre la corrupción en España. Transparency International España.

Zamora, R. \& Marín, J.A. (2010): "La representación simbólica del escándalo de corrupción política. Hacia una tipología de los marcos periodísticos (frames) utilizados en la narración del escándalo de corrupción política", en revista Razón y Palabra, ํㅜ 73, agosto-octubre. 
web:

http://www.razonypalabra.org.mx/N/N73/Varia73/34ZamoraMarin_V73.pdf

\section{Notas}

[1] Una definición muy similar, como reconoce el propio Malem, es la de Jiménez (1995: 23).

[2] Comisión de Peticiones del Parlamento Europeo. Ponente: Margrete Auken. Documento de sesión A60082/2009 20.2.2009

[3] Transparencia Internacional. Barómetro Global de la Corrupción 2010.

[4] Centro de Estudios Murcianos de Opinión Pública (CEMOP). Barómetro Región de Murcia Otoño 2010. Recuperado el 12 de diciembre de 2010 de la web: http://www.cemopmurcia.es/encuestas/barometro-region-demurcia-otono-2010/

\section{Profa. Dra. Rocío Zamora}

Profesora Agregada en la Facultad de Ciencias Sociales y de la Comunicación de la Universidad Católica San Antonio de Murcia (UCAM), donde imparte docencia en Opinión Pública y Comunicación Política. Asume el cargo de Vicedecana de Periodismo en dicha universidad. Es directora del Grupo de investigación en Comunicación, Política e Imagen de la UCAM.

\section{Juan Antonio Marín Albaladejo}

Doctorando del Departamento de Comunicación de la Universidad Católica San Antonio de Murcia (UCAM), trabaja actualmente en la última fase de su tesis doctoral sobre la corrupción política y su representación mediática.

Diploma de Estudios Avanzados (DEA) en Comunicación Audiovisual y Publicidad, Máster en Estudios Europeos y Licenciado en Periodismo.

Ha trabajado durante varios años en medios de comunicación españoles y en Bruselas (Bélgica).

\section{Forma de citar este artículo en bibliografías}

ZAMORA, R. y MARÍN ALBALADEJO, J.A. (2011): "Un modelo para analizar la representación simbólica del escándalo de corrupción política desde la teoría del framing: aplicación al 'caso Umbra'"en Revista PANGEA, 2, páginas 179 a 206. Red Académica Iberoamericana de Comunicación. Recuperado el de de 2 de: www.revistapangea.org 